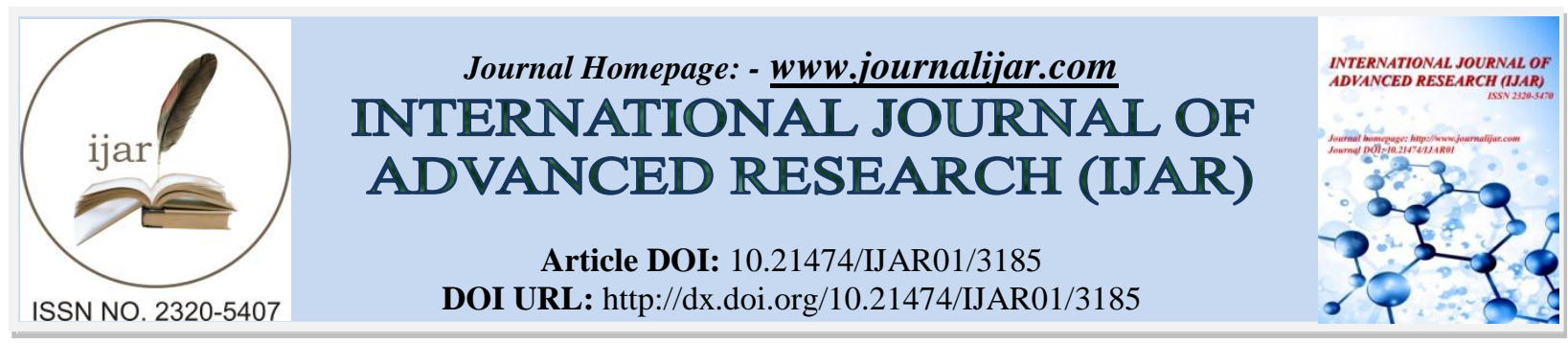

RESEARCH ARTICLE

\title{
INVESTIGATIONS ON PHOTOLUMINESCENCE PROPERTIES OF NANOCRYSTALLINE ZNO PARTICLES SYNTHESIZED BY SOL-GEL ROUTE.
}

\author{
Dept. of Physics, S. P. College, Pune, M.S., Pin -411030.
}

N. K. Wagholikar and "S. B. Jagtap.

\section{Manuscript Info}

Manuscript History

Received: 06 December 2016

Final Accepted: 15 January 2017

Published: February 2017

Key words:-

$\mathrm{ZnO}$-Nanoparticles, Sol-gel, annealing, photoluminescence.

\begin{abstract}
$\mathrm{ZnO}$ nanoparticles (ZnO-NPs) were synthesized using sol-gel method. The structural and optical properties were investigated by X-ray diffraction (XRD), scanning electron microscopy (SEM), and photoluminescence (PL). In this study, the effects of annealing temperature on photoluminescence (PL) of $\mathrm{ZnO}-\mathrm{NPs}$ were studied. $\mathrm{ZnO}$ was annealed at various temperatures between 500 and $800{ }^{\circ} \mathrm{C}$. The X-ray diffraction (XRD) results demonstrated that grain size increased with increase of annealing temperature. The average size of the nanoparticles was determined by SEM as well as XRD data and found to be $50 \mathrm{~nm}$ after annealing at $800{ }^{\circ} \mathrm{C}$. As the annealing temperature increased from 500 to $800{ }^{\circ} \mathrm{C}$, the intensities of both UV peak and that of green luminescence (GL) enhanced monotonously. The enhancement in the UV peak intensity is attributed to the decrease of grain boundaries and surface states; whereas, the remarkable improvement in the GL is assigned to the out-diffusion of oxygen from the sample up to $800{ }^{\circ} \mathrm{C}$. It supports that GL is induced by the singly ionized oxygen vacancies. These oxygen vacancies are saturated due to the finiteness of the defects at $800{ }^{\circ} \mathrm{C}$.
\end{abstract}

Copy Right, IJAR, 2017,. All rights reserved.

\section{Introduction:-}

$\mathrm{ZnO}$ is a promising material for short-wavelength photonic devices since it has a large direct band gap of $3.36 \mathrm{eV}$, and a large exciton binding energy of $60 \mathrm{meV}$, all of which are advantageous for light-emitting diode and lowthreshold optical pumped laser applications at room temperature. $\mathrm{ZnO}$ nanostructures, as well as $\mathrm{ZnO}$ films, have gathered considerable attention because they have a wide range of high technology applications like surface acoustic wave filters [1], photodetectors [2], light emitting diodes [3], photodiodes [4], gas sensors [5], and solar cells [6]. $\mathrm{ZnO}$ is also receiving a lot of attention because of its antibacterial property and its bactericidal efficacy has been reported to increase as the particle size decreases [7]. However, there is a compromise in the development of a method for preparing low cost $\mathrm{ZnO}-\mathrm{NPs}$ on a large scale and with high crystalline quality for optoelectronic application. Recently, several new ways have been developed to synthesize ZnO-NPs, such as the sonochemical method [8], oxidation process [9], sol-gel synthesis [10], a polymerization method [11], precipitation [12,13], solvothermal and hydrothermal methods [14-16], CVD [17,18], laser ablation [19] and sol-gel-combustion [20]. In general, the preparation of nanoparticles is a complicated process, and a wide variety of different variables may affect the properties of the final product. Some important variables have distinct effects on the properties of the final product, while others may have only minor effects. In the case of preparation of nanoparticles such as $\mathrm{ZnO}-\mathrm{NPs}$, it is very important to obtain a narrow size distribution of the final product, and to be able to control the morphology

*Corresponding Author:- S. B. JAGTAP.

Address:- Dept. of Physics, S. P. College, Pune , M.S., Pin - 411030. 
of the $\mathrm{ZnO}-\mathrm{NPs}$. This paper reports the synthesis of $\mathrm{ZnO}$ nanopowders through sol gel process. The as-grown $\mathrm{ZnO}-$ NPs were annealed at various temperatures to improve the crystalline quality and nanoparticle sizes. The structural properties and morphology of the synthesized and annealed ZnO-NPs were characterized by X-ray diffraction (XRD) and scanning electron microscopy (SEM) measurements, respectively. Low temperature photoluminescence (PL) spectra were used to investigate both the optical quality and property of the annealed ZnO-NPs. This is a key aspect for studying the applications of $\mathrm{ZnO}$ film in the UV region.

\section{Experimental Procedure:-}

The $\mathrm{ZnO}$ nanopowders (NPs) were grown from sol-gel method. The sol was prepared using zinc acetate dehydrate $\left[\mathrm{Zn}\left(\mathrm{CH}_{3} \mathrm{COO}\right)_{2} \cdot 2 \mathrm{H}_{2} \mathrm{O} ; 0.18 \mathrm{M}\right]$ as the starting material, methanol as the solvent, and citric acid $\left(\mathrm{C}_{6} \mathrm{H}_{8} \mathrm{O}_{7}\right)$ as the stabilizer. The precursor solution was mixed thoroughly with a magnetic stirrer in $80^{\circ} \mathrm{C}$ water bath until the formation of a sol. The sol was preheated in a furnace at $80^{\circ} \mathrm{C}$ for $10 \mathrm{~h}$ to evaporate the solvent and remove the organic residuals. The powders obtained from the dried sol were then annealed at different temperatures (500, 600,700 and $800{ }^{\circ} \mathrm{C}$ for $3 \mathrm{~h}$ at ambient air.

\section{Results and Discussion:-}

The XRD patterns of the as-synthesized $\mathrm{ZnO}$ nanoparticles and those annealed at temperatures of $500-800{ }^{\circ} \mathrm{C}$ for 2 $\mathrm{h}$ are shown in Fig. 1. Several significant peaks are shown. By comparing with the JCPDS No. 36-1451, the three pronounced diffraction peaks at about $2 \theta=31.8^{\circ}, 34.5^{\circ}$, and $36.3^{\circ}$ are identified, respectively, as the (100), (002), and (101) peaks of $\mathrm{ZnO}$. The results confirm the hexagonal wurtzite structure of the calcined ZnO NPs. By further increasing the calcination temperature, the three pronounced peaks showed enhanced intensity with reduced fullwidth at half-maximum (FWHM). It means that crystalline quality was improved and nanoparticle size was increased with annealing temperature. The results show improved crystalline quality of $\mathrm{ZnO}$-NPs by raising the calcinations temperature. The average particle size in the calcined ZnO- NPs was estimated by the Scherrer's relation. The approximate size of the as

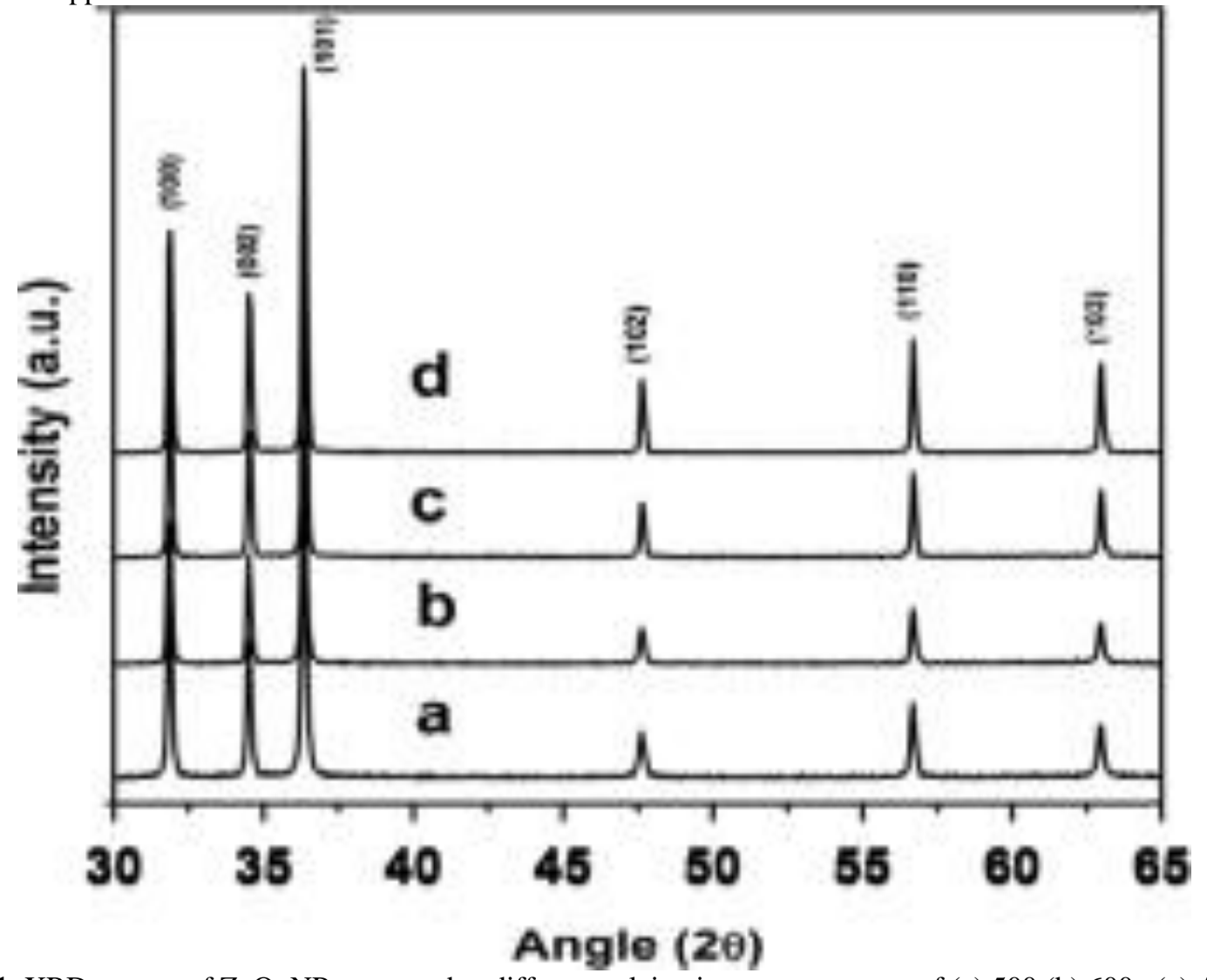

Fig. 1. XRD pattern of ZnO-NPs prepared at different calcinations temperatures of (a) 500 (b) 600, (c) 700 and (d) $800{ }^{\circ} \mathrm{C}$. 


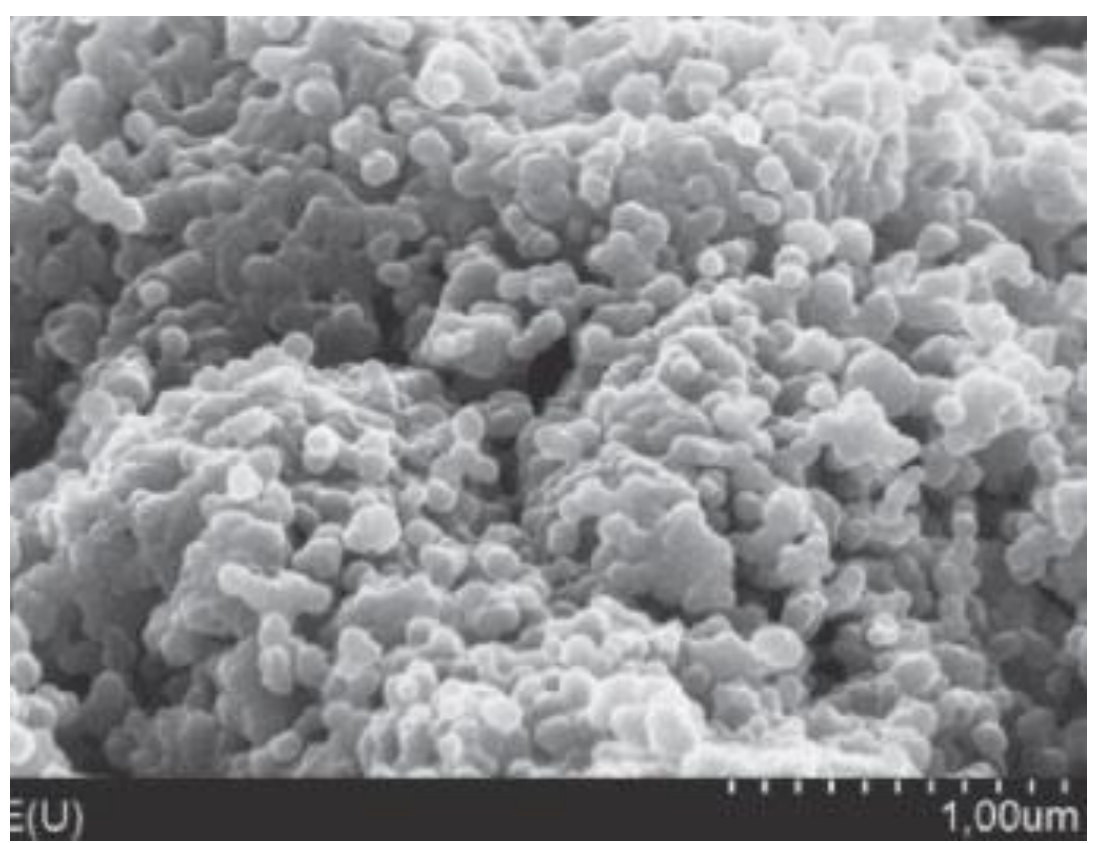

Fig. 2 SEM image of $\mathrm{ZnO}-\mathrm{NPs}$ after annealing at $800^{\circ} \mathrm{C}$

grown particles is close to $200 \mathrm{~nm}$. The average particle size of $\mathrm{ZnO}$ annealed at $500,600,700$, and $800{ }^{\circ} \mathrm{C}$ has been estimated to be about 18, 22, 30, and $52 \mathrm{~nm}$, respectively. The observation shows that by increasing the annealing temperature the crystalline quality and particles size of ZnO-NPs can be increased. The morphology and powder size of the annealed $\mathrm{ZnO}$ nanoparticles were studied by SEM. as shown in Fig. 2. The PL spectra from ZnO Fig. 3, consist of a UV emission band and a visible broadband emission. The UV emission is usually attributed to exciton recombination, while the visible luminescence is mainly due to point-like structural defects related to deep-level emissions, such as zinc vacancies, oxygen vacancies, interstitial zinc and interstitial oxygen.

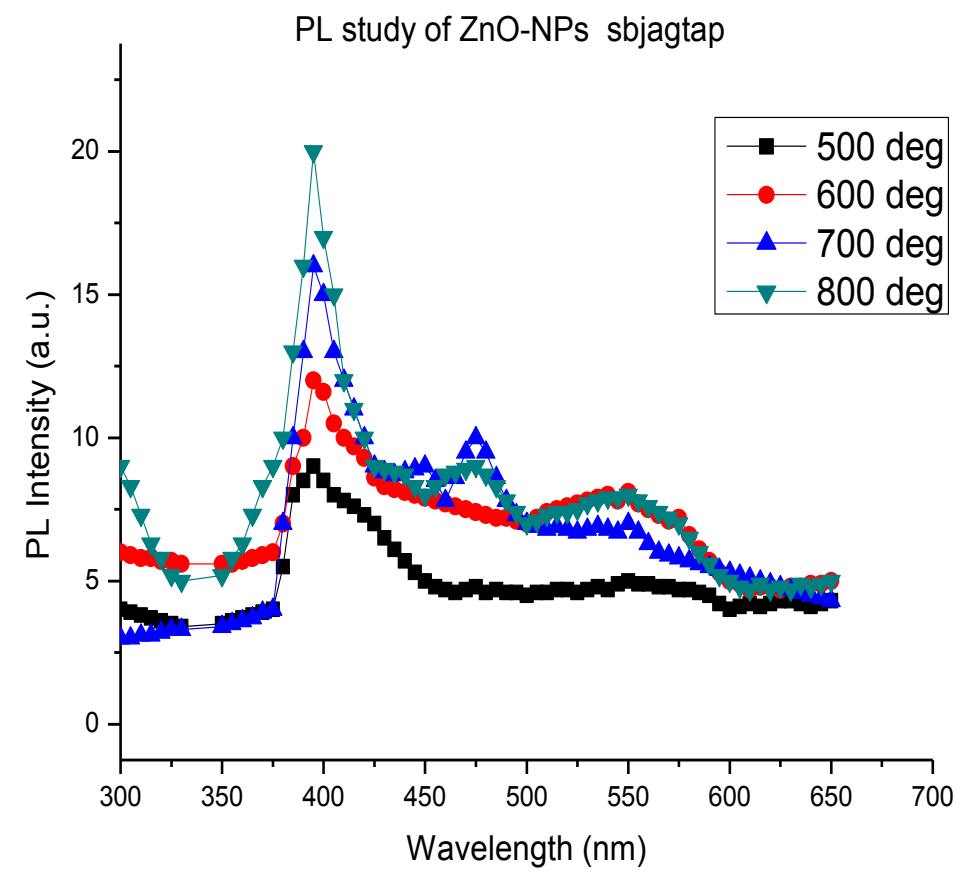

Fig.3 PL spectra of $\mathrm{ZnO}$ nanoparticles annealed at 500, 600, 700 and $800{ }^{\circ} \mathrm{C}$ 


\section{Conclusions:-}

$\mathrm{ZnO}$ nanoparticles were prepared using the sol-gel method. Sol-gel synthesis is inexpensive process and can be used for wide range of materials. XRD analysis at room temperature shows single phase formation of the sample with hexagonal crystal Symmetry and the crystalline quality was found to be enhanced by annealing temperature. After annealing at $800{ }^{\circ} \mathrm{C}$ the mean particle size estimated was found to be around $50 \mathrm{~nm}$ using Scherer's formula and SEM analysis shows the particle size to be $70 \mathrm{~nm}$. A sharp, strong and dominant UV emission with a suppressed green emission has been observed which confirms that the synthesized $\mathrm{ZnO}$ nanoparticles have good optical properties with low defects. This is a very promising step towards simple, low-cost and high quality synthesis of $\mathrm{ZnO}$ nano-powders.

Acknowledgements :

Authors are greatly thankful towards Principal Dr. D. N. Sheth for his kind and rigid support in extending the college facilities and infrastructure for this research. The encouragements from other staffs from department are also appreciated.

\section{References:-}

1. C. R. Gorla, N. W. Emanetoglu, S. Liang, W. E. Mayo, Y. Lu, M. Wraback, and H. Shen: J. Appl. Phys. 85 (1999) 2595.

2. S. Liang, H. Sheng, Y. Liu, Z. Hio, Y. Lu, and H. Chen: J. Cryst. Growth 225 (2001) 110.

3. N. Saito, H. Haneda, T. Sekiguchi, N. Ohashi, I. Sakaguchi, and K. Koumoto: Adv. Mater. 14 (2002) 418.

4. J. Y. Lee, Y. S. Choi, W. H. Choi, H. W. Yeom, Y. K. Yoom, J. H. Kim, and S. Im: Thin Solid Films 420-421 (2002) 112.

5. Q. Wan, Q. H. Li, Y. J. Chen, T. H. Wang, X. L. He, J. P. Li, and C. L. Lin: Appl. Phys. Lett. 84 (2004) 3654.

6. P. Ravirajan, A. M. Peiro, M. K. Nazeeruddin, M. Graetzel, D. D. C. Bradley, J. R. Durrant, and J. Nelson: J. Phys. Chem. B 110 (2006) 7635.

7. N. Padmavathy and R. Vijayaraghavan: Sci. Technol. Adv. Mater. 9 (2008) 35004.

8. C. Deng, H. Hu, G. Shao, C. Han, Materials Letters 64 (2010) 852-855.

9. Z.H. Wang, D.Y. Geng, Z. Han, Z.D. Zhang, Materials Letters 63 (2009) 2533-2535.

10. F. Bigdeli, A. Morsali, Materials Letters 64 (2010) 4-5.

11. P. Jajarmi, Materials Letters, Materials Letters 63 (2009) 2646-2648.

12. C.L. Kuo, C.L. Wang, H.H. Ko, W.S. Hwang, K.M. Chang, W.L. Li, H.H. Huang, Y.H. Chang, M.C. Wang, Ceramics International 36 (2010) 693-698.

13. R. Song, Y. Liu, L. He, Synthesis and characterization of mercaptoacetic acidmodified $\mathrm{ZnO}$ nanoparticles, Solid State Science 10 (2008) 1563-1567.

14. R. Razali, A.K. Zak, W.H.A. Majid, M. Darroudi, Ceramics International 37 (8) (2011) 3657-3663.

15. Q. Li, Z. Kang, B. Mao, E. Wang, C. Wang, C. Tian, S. Li, Materials Letters 62 (2008) 2531-2534.

16. H.Y. Xu, H. Wang, Y.C. Zhang, W.L. He, M.K. Zhu, B. Wang, H. Yan, Ceramics International 30 (2004) 9397.

17. R. Yousefi, M.R. Muhamad, A.K. Zak Thin Solid Films 518 (21) (2010) 5971-5977.

18. R. Yousefi, M.R. Muhamad, A.K. Zak, Current Applied Physics 11 (3) (2011) 767-770.

19. R. Zamiri, A. Zakaria, H.A. Ahangar, M. Darroudi, A.K. Zak, G.P.C. Drummen, Journal of Alloys and Compounds 516 (2012) 41-48.

20. A.K. Zak, M.E. Abrishami, W.H.A. Majid, R. Yousefi, S.M. Hosseini, Ceramics

21. International 37 (1) (2011) 393-398. 